\title{
Malaria treatment failures after artemisinin-based therapy in three expatriates: could improved manufacturer information help to decrease the risk of treatment failure ? Yves Jackson*1, François Chappuis ${ }^{1}$, Louis Loutan ${ }^{1}$ and Walter Taylor ${ }^{1,2}$
}

Address: ${ }^{1}$ Travel and Migration Medicine Unit, Geneva University Hospital, Rue Micheli-du-Crest 24, 1211 Geneva 14, Switzerland and ${ }^{2}$ UNICEF/ UNDP/World Bank/WHO Special Programme for Research and Training in Tropical Diseases, World Health Organisation, Av. Appia 20, Geneva, Switzerland

Email: Yves Jackson* - yves.jackson@hcuge.ch; François Chappuis - francois.chappuis@hcuge.ch; Louis Loutan - louis.loutan@hcuge.ch; Walter Taylor - bobtaylor@oucru.netnam.vn

* Corresponding author

Published: 04 October 2006

Malaria Journal 2006, 5:8I doi:10.1 |86/|475-2875-5-8|

This article is available from: http://www.malariajournal.com/content/5/I/8I

(c) 2006 Jackson et al; licensee BioMed Central Ltd

This is an Open Access article distributed under the terms of the Creative Commons Attribution License (http://creativecommons.org/licenses/by/2.0), which permits unrestricted use, distribution, and reproduction in any medium, provided the original work is properly cited.
Received: 17 March 2006

Accepted: 04 October 2006

\begin{abstract}
Background: Artemisinin-containing therapies are highly effective against Plasmodium falciparum malaria. Insufficient numbers of tablets and inadequate package inserts result in sub-optimal dosing and possible treatment failure. This study reports the case of three, non-immune, expatriate workers with $P$. falciparum acquired in Africa, who failed to respond to artemisinin-based therapy. Sub-therapeutic dosing in accordance with the manufacturers' recommendations was the probable cause.
\end{abstract}

Method: Manufacturers information and drug content included in twenty-five artemisinincontaining specialities were reviewed.

Results: A substantial number of manufacturers do not follow current WHO recommendations regarding treatment duration and doses.

Conclusion: This study shows that drug packaging and their inserts should be improved.

\section{Background}

Artemisinin derivatives, such as artesunate, artemether and dihydroartemisinin, are the most parasiticidal of all the antimalarial drugs against Plasmodium falciparum [1]. Their pharmacokinetic (rapid absorption, short half life $\sim 1$ hour) and pharmacodynamic (high parasite reduction ratio) properties mitigate against the development of resistance. In vivo resistance to this drug class has not yet been described [2]. However, several challenges remain, including the limited availability of GMP quality drugs, the emergence of fake drugs, and their optimal deployment in malaria-endemic countries. Artemisinin-based drugs are easily available in several malaria-endemic countries and are sold as mono- or combination therapies. They are manufactured in several countries, packaged differently and contain package inserts of varying quality and accuracy. WHO currently recommends malaria-endemic countries to use three days of an artemisinin-based combination treatment (ACT) e.g. artemether/lumefantrine $(\mathrm{A} / \mathrm{L})$, artesunate $(4 \mathrm{mg} / \mathrm{kg} /$ day $)$ plus an effective, longer acting partner drug, such as amodiaquine or mefloquine [3]. If used alone, seven days of treatment of an artemisinin derivative is necessary because shorter courses result in unacceptably high rates 
of recrudescence. Most recently, WHO has called drug manufacturers to switch the production of artemisinin monotherapies towards combined therapies because of the risk of developing drug resistance. Artesunate monotherapy of $\leq 5$ days duration in South-East Asian and African patients is associated with a failure rate of up to $50 \%$ and the four doses regimen of artemether/lumefantrine has resulted in failure rates of between 15 to $18 \%$ in African children, Thai adults and non immune travellers [411]. Recrudescent falciparum malaria is associated with a risk of developing severe malaria, especially in nonimmune individuals, such as travellers or expatriate workers.

Probable recrudescent $P$. falciparum malaria was recently diagnosed in three non-immune Europeans at the Geneva University Hospital. These three patients were initially treated in sub-Saharan Africa with artemisinin-based drugs. This motivated a thorough examination of package inserts of artemisinin-based drugs available in Africa. The potential association between treatment failure and inadequate information on drug leaflets are discussed in this study.

\section{Case report I}

Patient 1 was a 27 year old Swiss female working in Sudan for an international NGO. She was not taking antimalarial chemoprophylaxis. She developed a febrile illness that was diagnosed locally as malaria by positive microscopic examination (species and parasitaemia unknown) and Paracheck $^{\mathrm{TM}}$, a rapid diagnostic test that detects $P$. falciparum-specific histidine-rich II protein. By inference, she was infected with P.falciparum either alone or mixed with another Plasmodium species. She self-prescribed oral artemether, obtaining the drug from the NGOs pharmacy. She did not recall the dose of artemether, but she reported full compliance with the five days course contained in the package. She improved on this treatment, but four days after stopping artemether, she developed fever again and had a positive malaria blood smear (species and parasitaemia unknown) consistent with a recrudescence of her primary infection. She was retreated with the same five days regimen with good effect. Some three and a half weeks later, she suffered a recurrence of fever associated with a positive malaria smear (species and parasitaemia unknown) suggesting either a recrudescence of her initial infection or a new infection. PCR genotyping was unavailable to differentiate her recurrent illness. She received artemether for seven days in combination with a single dose (three tablets) of sulfadoxine/pyrimethamine and had no further episodes of malaria while in Sudan. On review at the Geneva Hospital six weeks after her last febrile episode, she was well and afebrile.

\section{Case report 2}

Patient 2 was a 35 years old Swiss woman working in rural Côte d'Ivoire for another international NGO. She was not on malaria prophylaxis. She developed fever and was found with a positive blood slide for malaria. Although the species was not specified, $P$. falciparum was the likely diagnosis given the high prevalence of $P$. falciparum locally. However, a mixed infection cannot be formerly ruled out. She was treated at a local clinic with a single dose of intramuscular quinine in combination with the four doses regimen (four tablets $\times 4$ over 48 hours) of artemether/lumefantrine (A/L); the latter is marketed as CoArtem $^{\circledast}$ in malaria endemic countries. She made an uneventful recovery and then started daily chloroquine/ proguanil (Savarine ${ }^{\circledast}$ ) as prophylaxis. Twelve days after completing her $\mathrm{A} / \mathrm{L}$, she presented at Geneva Hospital with fever and had a positive malaria slide, with a P.falciparum asexual parasitaemia of $4,000 / \mu \mathrm{L}$. She was treated successfully with three days of atovaquone/proguanil, remaining afebrile and aparasitaemic during 28 days of follow up.

\section{Case report 3}

Patient 3 was a 30 years old Swiss man who was working in Guinea Conakry. He took weekly mefloquine as prophylaxis and reported good compliance. However, he developed an acute febrile illness that was diagnosed as malaria by blood smear. He was unaware of the Plasmodium species but, considering the local malaria epidemiology, it was almost certainly $P$. falciparum. A local physician treated him with oral artesunate for three days and sulfadoxine/pyrimethamine, as a single dose of three tablets, with good effect. He did not recall the dose of artesunate but it was probably either $50 \mathrm{mg}$ bid or $100 \mathrm{mg}$ bid on the first day followed by $50 \mathrm{mg}$ twice a day, consistent with the artesunate formulations likely to be available locally. However, 14 days after as the last dose of artesunate, he presented in Geneva with fever and his blood slide was positive for P.falciparum with an asexual parasitaemia of $190,000 / \mu \mathrm{L}$, consistent with a probable recrudescence of his primary illness rather than a new infection (PCR unavailable). He was cured with the six doses regimen of artemether/lumefantrine.

In summary, these three non-immune expatriate workers suffered of probable falciparum malaria treatment failure after initial diagnosis and artemisinin-based treatment in Africa. It must be emphasized that the initial diagnosis could not be ascertained as malaria blood slides were not available for quality control. Considering the great variability in quality of diagnostic procedures in African laboratories, local diagnosis of malaria may not always be accurate. 
All patients reported having completed their treatment without episode of vomiting. The early timings of their recurrent malaria are consistent with recrudescence, but in the absence of PCR genotyping the possibility of early reinfections cannot be definitively excluded. Similarly, in the absence of defined plasmatic drug levels, none of these patients' recurrences meets the WHO definition of drug resistance [12]. Sub-optimal drug dosing is the likely explanation for the treatment failures in all three patients. Patient 1 took artemether for an inadequate duration (five days only) and suffered recurrent malaria four days after completing her treatment. Patient 2 failed with the four dose regimen of artemether/lumefantrine, an expected finding in non-immunes [9]. Patient 3 had probably taken insufficient artesunate during the first three days. His total dose was probably either $400 \mathrm{mg}$ (200 mg day 1, $100 \mathrm{mg}$ days $2 \& 3)$ or $300(100 \mathrm{mg} / \mathrm{d}) \mathrm{mg}$. These doses translate to a mean of 1.9 and $1.4 \mathrm{mg} / \mathrm{kg}$ daily, respectively, and are less than half of the current recommendation of $4 \mathrm{mg} / \mathrm{kg}$ ( $300 \mathrm{mg}$ for a $70 \mathrm{~kg}$ man) of artesunate daily when used in combination. However, the failure to clear parasites following an adult dose of sulfadoxine/ pyrimethamine $(\mathrm{S} / \mathrm{P})$ is consistent with $\mathrm{S} / \mathrm{P}$ resistance.

Several artemisinin-containing therapies and their packaging were reviewed in order to assess the role of inadequate manufacturer information and insufficient drug content as possible causes of malaria treatment failure in sub-Saharan Africa.

\section{Methods}

Packages of artemisinin-containing therapies currently sold in Africa were obtained from returning patients, WHO Roll Back Malaria, and the Internet. The list of twenty-five specialities presented here is not exhaustive (Table 1), but can reasonably be considered as representative of the current African market.

\section{Results}

The majority (10/17) of manufacturers of artemisinin monotherapies recommend five days of treatment instead of the WHO recommended seven days. Only three drug packages had paediatric dosing and none had specific recommendations for non-immune patients e.g. that 5 days of treatment is likely to be inadequate. Some packages contained less tablets than indicated in the package insert. The package inserts included in combination treatments were generally better, with doses both for children (7/8) and adults and with sufficient tablets to complete a therapeutic course. Of note was the use of the lower dose of mefloquine $(15 \mathrm{mg} / \mathrm{kg})$ rather than the higher dose $(25$ $\mathrm{mg} / \mathrm{kg}$ ) that is used in multidrug resistant areas of SE Asia.

\section{Discussion}

Sub-optimal antimalarial therapy results in increased morbidity and mortality of individuals living in malaria endemic areas, as well as travellers and expatriate workers $[13,14]$. Whilst well-established risk factors include poor compliance, fake drugs, limited training of drug vendors, high cost and drug resistance [15-17], little attention has focused on the number of packaged tablets and the quality of information in package inserts. Both are crucial elements in the successful treatment of malaria. Many patients in endemic countries buy antimalarial drugs without prior medical consultation from local markets, small shops, pharmacies and mobile street vendors. Most would probably assume that one drug package contains a therapeutic course. Travellers and field workers probably have the same assumptions as local residents. Clearly, drugs that are sold already packaged with insufficient tablets to make up a therapeutic course carry a risk of treatment failure, which is increased further, if not all of the packaged drugs are taken. Drugs at parasiticidal concentrations need to act on at least four asexual erythrocytic cycles to eliminate all asexual malaria parasites; thus, a minimum of six days of therapeutic drug concentrations is required [1]. Published data document failure rates of $50 \%$ with three days of artesunate in Africans, 50\% with five days of artesunate in Vietnamese patients, and 18\% with the for four doses regimen of artemether/lumefantrine in European travellers $[5,7,9]$.

This study shows that a substantial number of artemisinin-based drugs currently sold in Africa do not respect current WHO recommendations in term of treatment duration in case of monotherapy and many lack appropriate information regarding children dosage. Packages containing fewer pills than indicated in the manufacturers leaflet were also found. Concerning the use of low dose of mefloquine $(15 \mathrm{mg} / \mathrm{kg})$ in combination treatment, this may not be a problem in the short term in Africa where mefloquine as monotherapy or combined with artesunate has shown high efficacy in recent trials. Nevertheless, great care should be taken in monitoring cure rate, as this lower dose may potentially favour the development of mefloquine resistance [18-20].

\section{Conclusion}

Travellers, NGO and other workers should be aware not only of the hazards of contracting malaria, but also how to obtain optimal treatment. This is especially relevant for those who may be located in remote rural areas. Drug manufacturers should also play their part in reducing the risks of treatment failure. It is suggested that all currently available artemisinin-based monotherapies should be packaged for adults and children with a complete therapeutic course of seven days of treatment, that package inserts should be improved e.g. warning that a full course 
Table I: Examples of artemisinin-based monotherapies and combin
provided by the manufacturer on the accompanying package inser

\begin{tabular}{|c|c|c|c|c|c|c|c|}
\hline Trade name & Drug substance/s & $\begin{array}{l}\text { Tablet } \\
\text { strength (mg) }\end{array}$ & Adult dose/s (mg/day) & Paediatric dose/s (mg/day) & $\begin{array}{l}\text { Duratio } \\
\text { n (days) }\end{array}$ & $\begin{array}{l}\text { Tabletsl } \\
\text { package }\end{array}$ & Company \\
\hline \multicolumn{8}{|l|}{ Combination products } \\
\hline Artekin -02 & dihydroartemisinin + piperaquine & $40 / 320$ & $160 / 1280$ & $7-10$ y $80 / 640$ II -15 y $60 / 480$ & 2 & 8 & Hualijian \\
\hline Artekin & dihydroartemisinin + piperaquine & $40 / 320$ & $160 / 1280$ & $7-10$ y $80 / 640$ II -15 y $60 / 480$ & 2 & 8 & Holleykin pharmaceutical \\
\hline Duo-cotecxin & dihydroartemisinin+ piperaquine & $40 / 320$ & $160 / 1280$ & $7-10$ y $80 / 640$ II-15 60/480 & 2 & 8 & Beijing Holley-Cotec \\
\hline Coartem & artemether+ lumefantrine & $20 / 120$ & $\begin{array}{l}\text { DI } 160 / 960, \text { D2-3 80/480 } \\
\text { or DI-3 } 160 / 960\end{array}$ & $\begin{array}{l}5-15 \mathrm{~kg} 40 / 240 \quad 16-25 \mathrm{~kg} 80 / 480 \\
26-35 \mathrm{~kg} \mathrm{I} 120 / 720\end{array}$ & 3 & $16-24$ & Novartis \\
\hline Artequin & artesunate + mefloquine & $200 / 250$ & $200 / 250$ & NA & 3 & $3+3$ & Mepha \\
\hline Arsucam (infants and children) & artesunate + amodiaquine & $50 / 153$ & NA & $1-7$ y $50 / 1537-13$ y $100 / 306$ & 33 & $3+36+6$ & Sanofi-Aventis \\
\hline Arsucam (adults) & artesunate + amodiaquine & $50 / 153$ & $200 / 612$ & NA & 3 & $12+12$ & Sanofi-Aventis \\
\hline Larimal & artesunate + amodiaquine & $50 / 153$ & $200 / 612$ & $4 \mathrm{mg} / \mathrm{kg}(\mathrm{AS})+10 \mathrm{mg} / \mathrm{kg}(\mathrm{AM})$ & 3 & $12+12$ & Ipca \\
\hline \multicolumn{8}{|l|}{ Monotherapies } \\
\hline Artesunate tablets & artesunate & 50 & DI 200, D2-5 100 & NA & 5 & 6 & Guilin pharmaceutical \\
\hline Arinate & artesunate & 100 & DI 200, D2-5 100 & DI 3.2 mg/kg, D2-5 1.6 mg/kg & 5 & 6 & Dafra \\
\hline Arsumax & artesunate & 50 & DI 200, D2-5 100 & DI 4 mg/kg, D2-5 2 mg/kg & 5 & 12 & Sanofi-Aventis \\
\hline Cotexin & artesunate & 60 & DI 120, D2-5/7 60 & NA & $5-7$ & NA & Cotec \\
\hline Artesunate injection & artesunate & 60 & NA & NA & NA & NA & Guilin pharmaceutical \\
\hline Arte-biosorp & artesunate & 75 & 300 & NA & 7 & NA & Hovid \\
\hline Artenex & artesunate & NA & DI 4tab, D2-5 2tab & DI $3.2 \mathrm{mg} / \mathrm{kg}$, D2-5 $2 \mathrm{mg} / \mathrm{kg}$ & 5 & 12 & Kinapharma \\
\hline Malarin 200 & artesunate & 200 & DI 400, D2-5 200 & $\begin{array}{l}\text { DI } 4 \mathrm{mg} / \mathrm{kg}, \text { D2-5 } 2 \mathrm{mg} / \mathrm{kg} \\
\text { (infants) DI 200, D2-5 } 100 \\
\text { (children) }\end{array}$ & 5 & 6 & tri-health \\
\hline Plasmotrim 200 & artesunate & 200 & DI 400, D2-5 200 & NA & 5 & 6 & Mepha \\
\hline Plasmotrim 50 & artesunate & 50 & NA & DI 10 mg/kg, D2-5 5 mg/kg & 5 & 12 & Mepha \\
\hline Gvither forte kit injection & artemether & 80 & DI 240, D2-5 80 & DI 4 mg/kg, D2-5 2 mg/kg & 5 & 6 & Gvs labs \\
\hline Gvither forte tablets & artemether & 80 & DI 240, D2-5 80 & DI 4 mg/kg, D2-5 2 mg/kg & 5 & 6 & Gvs labs \\
\hline Larither capsule & artemether & 40 & DI $4 \mathrm{mg} / \mathrm{kg}$, D2-5 $2 \mathrm{mg} / \mathrm{kg}$ & NA & 7 & 6 & Ipca \\
\hline Capsulae artemetheri & artemether & 40 & DI 160, D2-5 80 & NA & $5-7$ & 10 & Kunming pharmaceutical \\
\hline Arte-biosorp & artemisinin & 75 & 150 & NA & 7 & 30 & Hovid \\
\hline Malaxin & dihydroartemisinin & 60 & DI 120, D2-5/7 60 & NA & 7 & 8 & $\begin{array}{l}\text { Cho dang } \\
\text { pharmaceutical }\end{array}$ \\
\hline Cotecxin & dihydroartemisinin & 60 & DI I20, D2-5/7 60 & DI 60, D2-7 30 & 7 & 8 & Jiaxing nanhu \\
\hline
\end{tabular}

Abbreviations: NA: information not available. DI,2,3: first, second, third day of treatment. Y: year. Tab: tablets 
of treatment must be taken even if patients feel well. In view of recent WHO recommendations, manufacturers should shift their production in favour of combined therapies rather than monotherapy to avoid the development of resistance for what is often called the 'last effective weapon against falciparum malaria'. Written information should avoid proposing different doses by trying to differentiate patients based on their presumed malaria immune status, as this may be confusing both for patients and prescribers. Similarly, packaging for combinations should be explicit, easy to use and contain the requisite number of tablets. Travellers should be aware that artemether/lumefantrine is known as Riamet ${ }^{\circledast}$ in temperate countries and CoArtem $^{\circledast}$ in malaria-endemic countries. Adult Riamet ${ }^{\circledast}$ contains 24 tablets (six dose regimen) but adult CoArtem ${ }^{\circledast}$ contains only 16 tablets ( 4 dose regimen). Setting international standards on package inserts might be a useful step that could be championed by a relevant international body. The training of local drug sellers and community health workers in malaria endemic countries is another strategy that could be adopted.

\section{Authors' contributions}

YJ: collected and analysed data and wrote the manuscript

FC: clinically managed the patients and co-supervised the study and the writing of the manuscript

\section{LL: co-supervised the study and revised the manuscript}

WT: collected data and co-supervised the writing of the manuscript

\section{Acknowledgements}

We are grateful to Dr A. Bosman (WHO/RBM) for his advice and for providing us with several drug packages. None of the authors got any financial support for this article. The views expressed in this article are those of the authors and not their affiliated institutions.

\section{References}

I. White NJ: Assessment of the pharmacodynamic properties of antimalarial drugs in vivo. Antimicrob Agents Chemother 1997, 4I:1413-1422

2. White NJ, Pongtavornpinyo W: The de-novo selection of drug resistance in malaria parasites. Philos Trans $R$ Soc Lond B Biol Sci 2003, 270:545-554.

3. WHO: Antimalarial drug combination therapy. Report of a WHO technical consultation. WHO/CDS/RBM/200I.35, Geneva, Switzerland 200I.

4. Ittarat W, Pickard AL, Rattanasinganchan P, Wilairatana P, Looareesuwan S, Emery K, Low J, Udomsangpetch R, Meshnick SR: Recrudescence in artesunate-treated patients with falciparum malaria is dependant on parasite burden not on parasite factors. Am J Trop Med Hyg 2003, 68: I 47-I52.

5. Nguyen DS, Dao BH, Nguyen PD, Nguyen VH, Le NB, Mai VS, Meshnick SR: Treatment of malaria in Vietnam with oral artesunate. Am J Trop Med Hyg 1993, 48:398-402.

6. Giao PH, Bihn TQ, Kager PA, Long HP, Van Thang N, Van Nam N, de Vries PJ: Artemisinin for treatment of uncomplicated malaria: is there a place for monotherapy? Am J Trop Med Hyg 200I, 65:690-695.
7. Borrmann S, Adegnika AA, Missinou MA, Binder RK, Issifou S, Schindler A, Matsiegui PB, Kun JF, Krishna S, Lell B, Kremsner PG: Shortcourse artesunate treatment of uncomplicated Plasmodium falciparum malaria in Gabon. Antimicrob Agents Chemother 2003, 47:90I-904

8. Sahr F, Willoughby VR, Gbakima AA, Bockarie MJ: Apparent drug failure following artesunate treatment of Plasmodium falciparum malaria in Freetown, Sierra Leone: four case reports. Ann Trop Med Parasitol 200I, 95:445-449.

9. van Agtmael M, Bouchaud O, Malvy D, Delmont J, Danis M, Barette S, Gras C, Bernard J, Touze JE, Gathmann I, Mull R: The comparative efficacy and tolerability of CGP 56697 (artemether + lumefantrine) versus halofantrine in the treatment of uncomplicated falciparum malaria in travellers returning from the Tropics to The Netherlands and France. Int J Antimicrob Agents 1999, 12:159-169.

10. Looareesuwan S, Wilairatana P, Chokejindachai W, Chalermrut K, Wernsdorfer W, Gemperli B, Gathmann I, Royce C: A randomized, double-blind, comparative trial of a new oral combination of artemether and benflumetol (CGP 56697) with mefloquine in the treatment of acute Plasmodium falciparum malaria in Thailand. Am J Trop Med Hyg 1999, 60:238-243.

II. Hatz C, Abdulla S, Mull R, Schellenberg D, Gathmann I, Kibatala P, Bek HP, Tanner M, Royce C: Efficacy and safety of CGP 56697 (artemether and benflumetol) compared with chloroquine to treat acute falciparum malaria in Tanzanian children aged I5 years. Trop Med Int Health 1998, 3:498-504.

12. WHO: Resistance of malarial parasites to drugs. World Health Organ Tech Rep Ser 529, Geneva, Switzerland 1965.

13. Trape JF, Rogier C: Combating malaria morbidity and mortality by reducing transmission. Parasitol Today 1996, I 2:236-240.

14. Kain KC, MacPherson DW, Kelton T, Keystone JS, Mendelson J, MacLean JD: Malaria deaths in visitors to Canada and in Canadian travellers: a case series. CMAJ 200I, I64:654-659.

15. Romi R, Boccolini D, Majori G: Malaria incidence and mortality in Italy in 1999-2000. Euro Surveill 200I, 6:143-147.

16. Dondorp AM, Newton PN, Mayxay M, Van Damme W, Smithuis FM, Yeung S, Petit A, Lynam AJ, Johnson A, Hien TT, Mc Gready R, Farrar J], Looareesuwan S, Day NP, Green MD, White NJ: Fake antimalarials in Southeast Asia are a major impediment to malaria control: multinational cross-sectional survey on the prevalence of fake antimalarials. Trop Med Int Health 2004, 9:124I-1246.

17. Marsh VM, Mutemi WM, Muturi J, Haaland A, Watkins WM, Otieno G, Marsh K: Changing home treatment of childhood fevers by training shop keepers in rural Kenya. Trop Med Int Health 1999 , 4:383-9.

18. Adam I, A-Elbasit IE, Elbashir MI: Efficacies of mefloquine alone and of artesunate followed by mefloquine for the treatment of uncomplicated, Plasmodium falciparum malaria in eastern Sudan. Ann Trop Med Parasitol 2005, 99: I I I-I I7.

19. Massougbodji A, Kone M, Kinde-Gazard D, Same-Ekobo A, Cambon $\mathrm{N}$, Mueller EA: A randomized, double-blind study on the efficacy and safety of a practical three-day regimen with artesunate and mefloquine for the treatment of uncomplicated Plasmodium falciparum malaria in Africa. Trans $R$ Soc Trop Med Hyg 2002, 96:655-9.

20. Simpson JA, Watkins ER, Price RN, Price RN, Aarons L, Kyle DE, White NJ: Mefloquine pharmacokinetic-pharmacodynamic models: implications for dosing and resistance. Antimicrob Agents Chemother 2000, 44:34|4-3424. 